\title{
Fetal first trimester growth is not associated with kidney outcomes in childhood
}

\author{
Hanneke Bakker ${ }^{1,2,3} \cdot$ Romy Gaillard ${ }^{1,2,3} \cdot$ Albert Hofman $^{2,4} \cdot$ Irwin K. Reiss $^{3}$ • \\ Eric A. P. Steegers ${ }^{5}$ Vincent W. V. Jaddoe ${ }^{1,2,3}$
}

Received: 19 January 2016 /Revised: 26 September 2016 / Accepted: 28 September 2016 / Published online: 27 October 2016

(C) The Author(s) 2016. This article is published with open access at Springerlink.com

\begin{abstract}
Background Impaired fetal growth is associated with increased risks of kidney diseases in later life. Because human development rates are highest during the first trimester, this trimester may be a particularly critical period for kidney outcomes. We have therefore examined the association of fetal first trimester growth with kidney outcomes in childhood.

Methods This study was embedded in a prospective population-based cohort study among 1176 pregnant women and their children. We used fetal first trimester crown-length as the growth measure among mothers with a regular menstrual cycle and a known first day of the last menstrual period. At the childhood age of 6 (median 5.7-6.8) years, we measured combined kidney volume, microalbuminuria and estimated glomerular filtration rate (eGFR) based on serum creatinine and cystatin $\mathrm{C}$ concentrations.

Results No consistent associations of fetal first trimester crownrump length with childhood combined kidney volume, eGFR
\end{abstract}

Electronic supplementary material The online version of this article (doi:10.1007/s00467-016-3537-8) contains supplementary material, which is available to authorized users.

Vincent W. V. Jaddoe

v.jaddoe@erasmusmc.nl

1 The Generation R Study Group (Na-29-15), Erasmus University Medical Center, Box 2040, 3000 CA Rotterdam, The Netherlands

2 Department of Epidemiology, Erasmus University Medical Center, Rotterdam, The Netherlands

3 Department of Pediatrics, Erasmus University Medical Center, Rotterdam, The Netherlands

4 Department of Epidemiology, Harvard T.H. Chan School of Public Health, Boston, MA, USA

5 Department of Obstetrics \& Gynaecology, Erasmus University Medical Center, Rotterdam, The Netherlands and microalbuminuria were observed. Compared to children with a fetal first trimester crown-rump length in the highest quintile, those in the lowest quintile had a larger childhood combined kidney volume (difference $5.32 \mathrm{~cm}^{3}, 95 \%$ confidence interval 1.06 to 9.57), but no differences in kidney function. Conclusion Our results do not support the hypothesis that fetal first trimester growth restriction affects kidney size and function in childhood. Further studies are needed to focus on critical periods in early life for kidney function and disease in later life.

Keywords Fetal development · Crown-rump length $\cdot$ Kidney function $\cdot$ Childhood $\cdot$ Kidney volume

\section{Introduction}

Chronic kidney disease (CKD) may originate in the earliest phase of life [1]. It has been hypothesized that adverse environmental exposures in utero may lead to kidney developmental adaptations, including lower nephron numbers leading to glomerular hyperfiltration [2-4]. These adaptations may subsequently progress to glomerulosclerosis, impaired kidney function and increased risks of CKD in adulthood [5, 6]. This hypothesis is supported by observational studies showing associations of preterm birth or small-size for gestational age at birth with smaller kidneys and increased risk of kidney disease later in life [7-9]. In an earlier study, our group observed that decreased second and third trimester fetal growth and lower infant growth rates are associated with smaller kidneys in childhood [8]. We also noted that decreased second and third trimester fetal weight growth is associated with lower kidney function in childhood [8]. To date, little is known about the influence of first trimester fetal development on kidney outcomes later in life. Nephrogenesis starts around the eighth week of gestation and ceases around 36 weeks of gestation [10]. Because of the 
relatively high developmental rates, first trimester might also be a critical period for kidney development. Fetal first trimester crown-rump measurement is often used to determine gestational age in obstetric care practice which suggests there is no variation in early fetal growth [11]. However, we have previously shown that in women with a regular cycle and a known first day of their menstrual period, fetal first trimester crownrump length can also be used to assess differences in embryonic growth rate $[11,12]$.

We assessed, in a population-based prospective cohort study involving 1176 mothers and their children, the associations between fetal first trimester crown-rump length and kidney outcomes in childhood. Kidney outcomes included combined kidney volume, estimated glomerular filtration rate (eGFR) based on creatinine and cystatin $\mathrm{C}$ blood levels and microalbuminuria. Since kidney function tracks from childhood into adulthood, subclinical variations at young age might already be associated with renal impairment in later life $[7,8]$.

\section{Methods}

\section{Design and study population}

This study was embedded in the Generation R Study, a population-based prospective cohort study from fetal life onwards in Rotterdam, the Netherlands [13]. As previously described, inclusion in the study was aimed at women in the early stages of pregnancy but enrollment was allowed until birth [14]. Of the total study cohort of 9901 mothers, 1630 mothers had an available fetal first trimester crown-rump measurement within the range of 10 weeks 0 days to 13 weeks 6 days and had a reliable gestational age estimate based on the last menstrual period and a regular menstrual cycle, and were therefore eligible for enrollment in this study [12]. We included only mothers who gave birth to a singleton live-born child $(n=1619)$. In total, 1176 mothers and children were included in the detailed follow-up measurements at the age of 6 years. Blood and urine samples for kidney function measurements were available in $793(67 \%)$ and 1141 (98 \%) children, respectively. Missing blood samples were mainly due to lack of consent. A flowchart of the study design is given in Fig. 1. Differences in subject characteristics between children with and without blood samples are shown in Electronic Supplemental Material (ESM) Table 1. There were no differences in fetal first trimester crown-rump length between children with and without blood sample measurements.

\section{Fetal first trimester crown-rump length}

Fetal first trimester crown-rump length measurements were carried out in the gestational age range of 10 week 0 days to 13 weeks 6 days in a true mid-sagittal plane with the genital tubercle and the fetal spine longitudinally in view on the ultrasound scan [12]. Intraclass correlation coefficients were $\geq 0.995$ [15]. Information on the first day of the last menstrual cycle was obtained from the referring letter from the midwife or hospital and was confirmed at enrollment [12]. Mothers gave additional information on the regularity and duration of the menstrual cycle at the ultrasound visit. Gestational age adjusted standard deviation scores (SDS) for first trimester crow-rump length were constructed as described by MookKanamori et al. [12].

\section{Childhood kidney outcomes}

The left and right kidney biometrics of each child at the median age of 6 (90\% range 5.7-6.8) years were measured as described previously $[8,16]$. The child was awake and calm in a standardized prone position during the ultrasound examination. Maximal bipolar kidney length, width and depth were measured; kidney width and depth were measured at the level of the hilum. The cross-sectional area in which the kidney appeared symmetrically round at its maximum width was used. Kidney volume was calculated using the equation of an ellipsoid: volume $\left(\mathrm{cm}^{3}\right)=0.523 \times$ length $(\mathrm{cm}) \times$ width $(\mathrm{cm}) \times$ depth $(\mathrm{cm})$ [17]. Combined kidney volume was calculated by summing right and left kidney volume. Previously reported intra-observer and inter-observer correlation coefficients were used [18].

Blood samples were drawn by antecubital venipuncture. Serum creatinine levels were measured using an enzymatic method on a Cobas c502 analyzer (Roche Diagnostics $\mathrm{GmbH}$, Mannheim, Germany), and serum cystatin C levels were measured using a particle-enhanced immunoturbidimetric assay on Cobas c702 analyzer (Roche Diagnostics GmbH). Intra- and inter-assay coefficients were used a described previously [19]. The eGFR was calculated according to the revised Schwartz 2009 formula [20]: eGFR creat $=36.5 \times$ [height $(\mathrm{cm}) /$ serum creatinine ( $\mu \mathrm{mol} / 1$ ] [20]. The eGFR based on cystatin $\mathrm{C}$ levels according to the Zappitelli formula [21] was also calculated: $\mathrm{eGFR}_{\mathrm{Cyst}}=75.94 /\left[\mathrm{CysC}^{1.17}\right][16]$. Urine creatinine $(\mathrm{mmol} / \mathrm{l})$ and urine albumin $(\mathrm{mg} / \mathrm{l})$ levels were determined on a Beckman Coulter AU analyzer (Beckman Coulter Inc., Brea, CA); creatinine levels were measured according to the Jaffe method. The albumin:creatinine ratio was calculated, and microalbuminuria was defined as an albumin:creatinine ratio of between 2.5 and $25 \mathrm{mg} / \mathrm{mmol}$ for boys, and between 3.5 and $25 \mathrm{mg} / \mathrm{mmol}$ for girls [22].

\section{Covariates}

Information on maternal age, pre-pregnancy weight, parity, ethnicity, educational level, smoking during pregnancy, alcohol consumption during pregnancy, folic acid supplementation during pregnancy and breastfeeding was obtained by 
Fig. 1 Flowchart of study design showing the inclusion of participants in the analyses

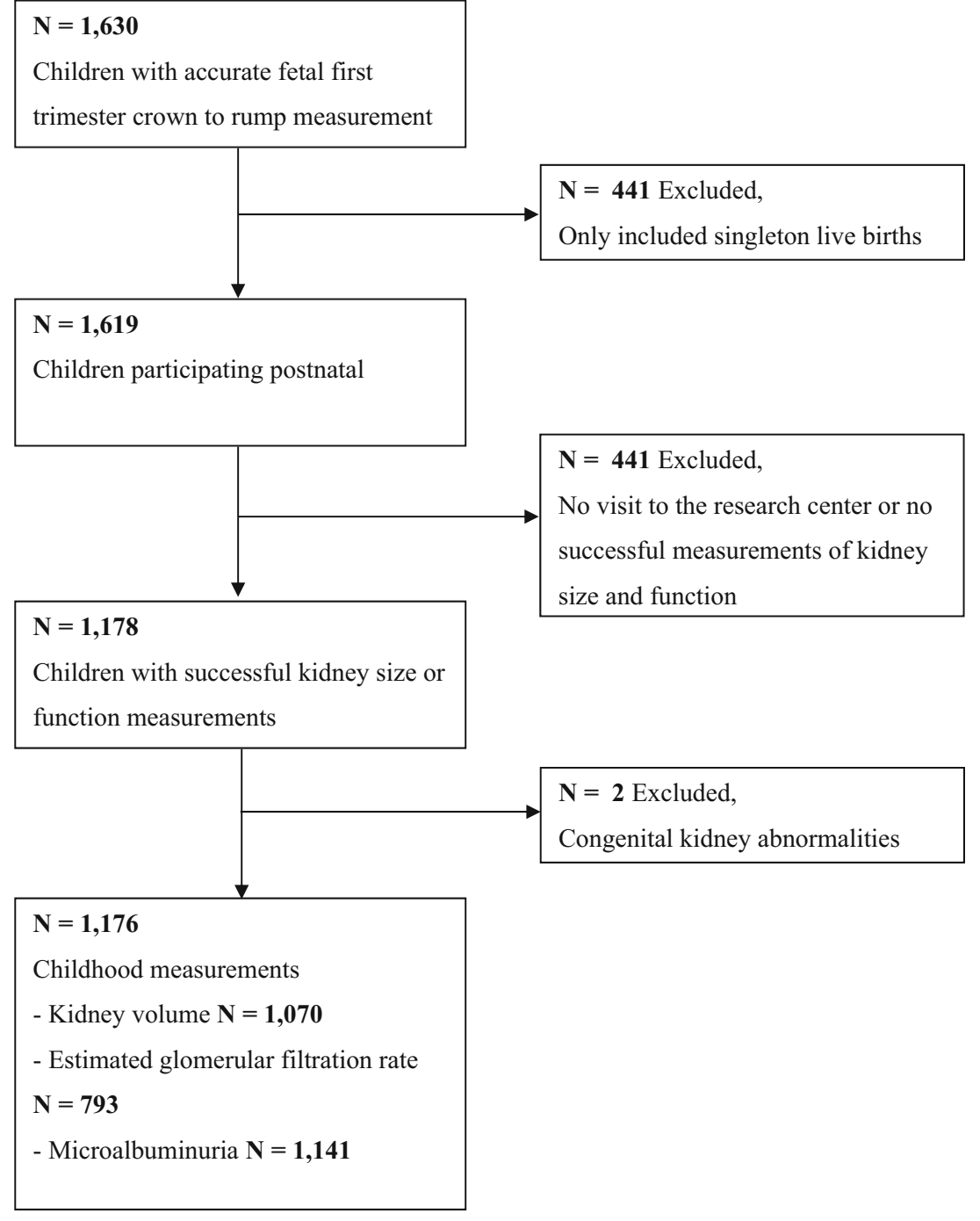

questionnaires and registries. Maternal height was measured without shoes, and pre-pregnancy body mass index (BMI) was calculated. Date of birth, infant sex and birth weight were obtained from midwife and hospital registries. At the age of 6 years, child height and weight were measured without shoes and heavy clothing, and body surface area (BSA) was calculated using the DuBois formula $\left(\mathrm{BSA}=\right.$ weight $(\mathrm{kg})^{0.425} \times$ height $\left.(\mathrm{cm})^{0.725} \times 0.007184\right)$ [23].

\section{Statistical analyses}

First, we analyzed the associations of fetal first trimester crown-rump length with childhood kidney outcomes (kidney volume, eGFR based on creatinine and cystatin C levels and microalbuminuria) by using multiple linear and logistic regression models. We used first trimester crown-rump length SDS as continuous variables and as quintiles to explore non-linear associations. Sensitivity analyses were performed using tertiles of fetal first trimester growth. To explore the associations of lower and higher growth as compared to average growth, we compared the lowest and the highest tertile with the middle tertile. The fully adjusted model was adjusted for maternal age, educational level, ethnicity, parity, pre-pregnancy BMI, smoking during pregnancy, alcohol consumption during pregnancy, folic acid supplement use, breastfeeding and current BSA. To take into account body composition, analyses focused on total kidney volume were indexed for BSA. Analyses focused on eGFR were not adjusted for childhood BSA since height is included in the Schwartz 2009 formula [20]. Potential confounders were based on their associations with kidney outcomes or a change in the effect estimate of $>10 \%$. To reduce the possibility of potential bias due to missing data, we imputed missing data of the fetal, child and maternal covariates with five imputations and analyzed these datasets together [24]. Additional information on the imputation procedure is given in the ESM. All statistical analyses were performed using the Statistical Package for the Social Sciences version 21.0 for Windows (IBM Corp., Armonk, NY). 


\section{Results}

\section{Subject characteristics}

Maternal, fetal and child characteristics are shown in Table 1. Mean fetal first trimester crown-rump length was 61.1 (SD 11.4) $\mathrm{mm}$ at a median gestational age of 12.4 (90\% range
11.0-13.7) weeks. At the median age of 6.0 (90\% range 5.76.8) years, mean combined kidney volume was 119.7 (SD 22.0) $\mathrm{cm}^{3}$, creatinine-based eGFR was 119.4 (SD 15.4) $\mathrm{ml} /$ min per $1.73 \mathrm{~m}^{2}$ and cystatin $\mathrm{C}$ based eGFR was 102.8 (SD 15.9) $\mathrm{ml} / \mathrm{min} / 1.73 \mathrm{~m}^{2}$. Microalbuminuria was present in $7.0 \%$ of all children. Correlations between total kidney volume and BSA-related kidney volume with eGFR based on creatinine
Table 1 Maternal and child characteristics

\begin{tabular}{|c|c|}
\hline Maternal and child characteristics $(N=1176)$ & Values \\
\hline \multicolumn{2}{|l|}{ Maternal characteristics } \\
\hline Age (years) & $31.8(22.8-38.1)$ \\
\hline Height (cm) & $168.8(\mathrm{SD} 7.1)$ \\
\hline Pre-pregnancy weight (kg) & $67.0(\mathrm{SD} 11.8)$ \\
\hline Pre-pregnancy body mass index $\left(\mathrm{kg} / \mathrm{m}^{2}\right)$ & $23.5(\mathrm{SD} 3.9)$ \\
\hline Parity, nulliparous & $715(60.8 \%)$ \\
\hline \multicolumn{2}{|l|}{ Ethnicity } \\
\hline European & $853(72.5 \%)$ \\
\hline Non -European & $323(27.5 \%)$ \\
\hline \multicolumn{2}{|l|}{ Educational level } \\
\hline No higher education & $525(44.6 \%)$ \\
\hline Higher education & $651(55.4 \%)$ \\
\hline \multicolumn{2}{|l|}{ Smoking } \\
\hline Non-smoking & $881(74.9 \%)$ \\
\hline Continued smoking & $295(25.1 \%)$ \\
\hline \multicolumn{2}{|l|}{ Folic acid supplement use } \\
\hline No use & $156(13.3 \%)$ \\
\hline First 10 weeks use & $376(32.0 \%)$ \\
\hline Preconception use & $644(54.8 \%)$ \\
\hline \multicolumn{2}{|l|}{ Fetal characteristics } \\
\hline Gestational age at fetal crow-rump length (weeks) & $12.4(11.0-13.7)$ \\
\hline First trimester fetal crown-rump length (mm) & $61.1(\mathrm{SD} 11.4)$ \\
\hline \multicolumn{2}{|l|}{ Birth and infant characteristics } \\
\hline Males & $570(\mathrm{SD} 48.5)$ \\
\hline Gestational age (weeks) & $40.1(37.1-42.0)$ \\
\hline Birth weight (g) & $3,459.2(\mathrm{SD} 549.9)$ \\
\hline \multicolumn{2}{|l|}{ Breastfeeding } \\
\hline No & $92(7.8 \%)$ \\
\hline Yes & $1084(92.2 \%)$ \\
\hline \multicolumn{2}{|l|}{ Child characteristics } \\
\hline Age (years) & $6.0(5.7-6.8)$ \\
\hline Height $(\mathrm{cm}$ & $119.0(\mathrm{SD} 5.5)$ \\
\hline Weight (kg) & $22.9(\mathrm{SD} 3.7)$ \\
\hline Body mass index $\left(\mathrm{kg} / \mathrm{m}^{2}\right)$ & $16.1(\mathrm{SD} 1.7)$ \\
\hline Kidney volume combined $\left(\mathrm{cm}^{3}\right)$ & $119.7(\mathrm{SD} 22.0)$ \\
\hline eGFR (Schwartz, creatinine based) $\left(\mathrm{ml} / \mathrm{min}\right.$ per $\left.1.73 \mathrm{~m}^{2}\right)$ & $119.4(\mathrm{SD} 15.4)$ \\
\hline eGFR (Zappitelli, cystatin C based), (ml/min per $\left.1.73 \mathrm{~m}^{2}\right)$ & $102.8(\mathrm{SD} 15.9)$ \\
\hline Microalbuminuria & $82(7 \%)$ \\
\hline
\end{tabular}

Values in the table are given as the mean with the standard deviation (SD) in parenthesis, as the median with the $90 \%$ range in parenthesis or as the number of subjects with the percentage in parenthesis

eGFR, Estimated glomerular filtration rate 
and cystatin levels are given in ESM Tables 4 and 5. In total 117 children were born with a small size for gestational age at birth $(<10 \%)$ and $54(4.6 \%)$ children were born preterm $(<37$ weeks).

\section{Fetal first trimester crown-rump length and kidney outcomes in childhood}

Table 2 presents the analyses focused on the associations between fetal first trimester crown-rump length and kidney volume and function. Fetal first trimester crown-rump length SDS was not associated with kidney volume and eGFR. There was also no association of fetal first trimester crownrump length SDS with the risk of microalbuminuria (all $p$ values $>0.05$ ).

To investigate non-linearity, we created quintiles of fetal first trimester growth. Table 2 shows that as compared to the highest quintile of fetal first trimester crown-rump length, the lowest quintile was associated with a larger childhood combined kidney volume (difference $5.32 \mathrm{~cm}^{3}, 95 \%$ confidence interval 1.06-9.57), but not with eGFR and microalbuminuria. Sensitivity analyses using tertiles of fetal first trimester crown-rump length showed no associations with childhood kidney outcomes. Results of this sensitivity analyses are presented in ESM Table 3; observed data before multiple imputations are presented in ESM Table 2. The association of fetal first trimester crown-rump length with childhood kidney volume was not observed in non-imputed data; in addition analyses of non-imputed data showed no associations with other kidney outcomes in childhood. The lack of significant associations in non-imputed datasets may be due to the smaller numbers: analyses on imputed data were based on 1176 datasets, whereas analyses on the non-imputed data were based on 934 datasets.

\section{Discussion}

In this population-based prospective cohort study, we evaluated the associations of fetal first trimester crown-rump length with kidney growth and function in childhood. We did not observe consistent associations of fetal first trimester growth with kidney outcomes in childhood.

Some methodological issues need to be addressed. We used a subgroup of a large population-based prospective cohort study to examine the kidney consequences of fetal first trimester growth restriction. Only mothers with a first trimester crown-rump measurement and a reliable first day of their last period were eligible for entry into the study, and women meeting these criteria represented only a small subgroup of the full study. We used the first day of the last menstrual period in women with a regular menstrual cycle to date gestational age since we could not measure the timing of ovulation and implantation. It is therefore possible that a misclassification of gestational age could have occurred [25]. Of the eligible subgroup, blood samples had been collected from $67 \%$ of all children. Our results would be biased if the results differed between children with and without follow-up measurements at the age of 6 years. Although this possibility seems unlikely, we cannot exclude it. Children for whom no blood samples were available had a lower mean birth weight than their counterparts for whom blood samples were available. Our results would be biased if the associations of first trimester growth with childhood kidney function differed between children with and without blood samples. Since smaller numbers of blood samples were available in children with lower birth weight, our observed effect estimates may be underestimated. Glomerular number cannot be evaluated in vivo, but

Table 2 Fetal first trimester growth quintiles and childhood kidney volume and function in the 1176 children enrolled in the study

\begin{tabular}{lllll}
\hline $\begin{array}{l}\text { Crown-rump quintiles in } \\
\text { standard deviation scores }\end{array}$ & $\begin{array}{l}\text { BSA-adjusted combined } \\
\text { kidney volume }\left(\mathrm{cm}^{3}\right)\end{array}$ & $\mathrm{GFR}_{\text {creat }}\left(\mathrm{ml} / \mathrm{min} \text { per } 1.73 \mathrm{~m}^{2}\right)^{\mathrm{a}}$ & $\mathrm{GFR}_{\text {Cys }}\left(\mathrm{ml} / \mathrm{min} \text { per } 1.73 \mathrm{~m}^{2}\right)^{\mathrm{a}}$ & $\begin{array}{l}\text { Microalbuminuria } \\
(\mathrm{mg} / \mathrm{mmol})(\mathrm{OR})\end{array}$ \\
\hline $1(N=238)$ & $5.32(1.06,9.57)^{*}$ & $0.24(-3.33,3.80)$ & $-0.67(-4.47,3.14)$ & $0.60(0.25,1.44)$ \\
$2(N=234)$ & $-0.88(-5.14,3.38)$ & $-0.34(-3.93,3.26)$ & $-2.69(-6.53,1.15)$ & $0.92(0.42,2.02)$ \\
$3(N=234)$ & $0.42(-0.85,4.68)$ & $-0.26(-3.83,3.31)$ & $0.33(-3.48,4.14)$ & $1.13(0.52,2.44)$ \\
$4(N=237)$ & $0.54(-3.75,4.83)$ & $1.04(-2.54,4.64)$ & $-1.11(-4.96,2.73)$ & $1.41(0.66,2.96)$ \\
$5(N=233)$ & Reference & Reference & Reference & Reference \\
$p$ value for trend & 0.10 & 0.58 & 0.83 & 0.51 \\
\hline
\end{tabular}

$* p$ value $<0$

Values in table are regression coefficients with the $95 \%$ confidence interval in parenthesis and reflect the difference in childhood kidney outcomes between first-trimester crown-rump length (Quintile 5 is the reference group) The model is adjusted for duration of last menstrual cycle, sex and age of child at time of outcome measurements, maternal age, educational level, ethnicity, parity, pre-pregnancy body mass index, smoking during pregnancy, alcohol consumption during pregnancy, folic acid supplement use, breastfeeding and current childhood body surface area. Analyses on microalbuminuria are Odds Ratio's

BSA, Body surface area

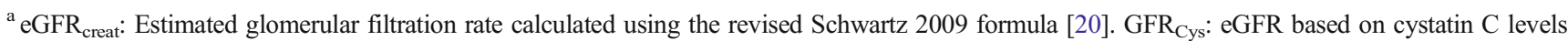
according to the Zappitelli formula [21]. 
kidney size and glomerular number correlate in pathological studies in childhood and adulthood [26-28]. We estimated the GFR using the Schwartz formula [20], which is based on serum creatinine levels, and the Zappitelli formula [21], which is based on serum cystatin C levels; both formulas have been validated in pediatric populations. The eGFR was higher when calculated based on creatinine concentrations than on cystatin $\mathrm{C}$ concentrations, a difference which is in line with previous studies [29]. However, no difference in results were observed when we used eGFR based on creatinine concentrations compared to cystatin $\mathrm{C}$ concentrations, and we found no differences in outcomes between those formulas. It has been suggested that serum cystatin $\mathrm{C}$ levels may be the superior biomarker for evaluating kidney function compared to serum creatinine levels [30]. However, to date it is not clear which formula provides the best estimation of the GFR [30]. We used a random urine sample to determine the albumin to creatinine ratio to evaluate microalbuminuria. Since intra-individual variation in urinary albumin secretion may be large, the variability would probably have been lower if we collected first morning void samples [31]. Finally, although we adjusted for several potential confounders, residual confounding might still be a problem because of the observational design of the study.

Growth and development rates are higher in fetal life than in childhood. The highest rate of organogenesis in humans occurs during the first trimester. The first trimester may therefore be a critical period in terms of developing risk factors for diseases in later life. We adopted an approach used in previous studies focused on fetal first trimester growth in relation to birth outcomes and cardiovascular outcomes and used quintiles for fetal first trimester growth $[12,14]$. No major differences in results were observed when we used tertiles of fetal first trimester growth instead of quintiles. Longitudinal studies, including studies based on the same cohort as that in the present study, have shown associations of impaired first trimester growth with increased risks of premature birth, low birth weight and being small for gestational age at birth [12, 32, 33]. Results from this cohort study have also previously shown that fetal first trimester growth restriction is associated with cardiovascular risk factors in childhood [14]. The analyses in this study were performed in a healthy population, with the majority of children born at term and normal weight for gestational age. To the best of our knowledge, no other human studies have evaluated the associations of first trimester growth with kidney function in later life. Nephrogenesis starts around week 5 of gestation, and the first nephrons begin to form at approximately week 9 [34]. Nephrogenesis continues during gestation and stops around week 34-36 [10]. Against this background, our aim was to identify the role of first trimester fetal development in kidney development.

Using data from the same cohort as that enrolled in the present study, we previously reported that lower fetal growth from second trimester onwards is associated with lower combined kidney volume and eGFR in childhood [8]. Also, a previous study among children born preterm showed that size for gestational age is correlated with kidney volume at the ages of 0,3 and 18 months, which implies that impaired fetal growth has consequences for kidney growth in infancy [35]. Some studies on fetal growth impairment have shown a slight catch-up kidney growth postnatally in small for gestational age infants, but the results are inconclusive $[35,36]$. The current study extends these previous findings since it is focused on first trimester of pregnancy, a period of which little is known in relation to kidney outcomes. We did not observe consistent associations of fetal first trimester growth with kidney outcomes in childhood.

Smaller kidneys with fewer nephrons will lead to compensatory glomerular hyperfiltration, which might be beneficial in the short term but can lead to glomerulosclerosis and impaired kidney function in later life [1]. Hyperfiltration might increase renal mass while glomerular number is relatively low [37]. However, it is not possible to distinguish hypertrophy or normal growth by ultrasonography. Also, it is not known when hypertrophy exactly occurs, and it is difficult to determine whether glomerular enlargement is caused by glomerular hyperfiltration $[38,39]$. In the present study, we observed an inverse association between fetal first trimester crown-rump length and kidney volume in childhood, which we cannot fully explain. This finding is in line with the results of a previous study from the same cohort which showed that the lowest tertile of gestational ageadjusted abdominal circumference in the third trimester is associated with a larger relative fetal kidney volume [40]. Renal hypertrophy may be one explanation for this inverse association; however, more studies are needed to replicate our findings and to identify the underlying mechanisms.

We performed multiple statistical tests. However, since the kidney outcomes were highly correlated, we did not adjust analyses for multiple testing. Therefore, the observed association between the lowest first trimester crown-rump length and kidney volume should be interpreted carefully and may be a chance finding. Decreased fetal growth might lead to impaired kidney function by other mechanisms than smaller kidneys; for example, multiple studies have suggested that epigenetic changes in response to adverse fetal exposures lead to developmental adaptations $[6,41,42]$.

In conclusion, we did not observe associations between fetal first trimester growth restriction and kidney size and function in childhood. These findings do not support the hypothesis that the first trimester is a critical period for kidney function in later life, and further studies on this hypothesis are needed. 
Acknowledgments The Generation R study is being conducted by the Erasmus Medical Center and Erasmus University Rotterdam in close collaboration with the Municipal Health Service Rotterdam area, Rotterdam and the Stichting Trombosedienst \& Artsen laboratorium Rijnmond, Rotterdam. We gratefully acknowledge the contributions of children and their parents, general practitioners, hospitals, midwives and pharmacies in Rotterdam.

Compliance with ethical standards Written informed consent was obtained from all parents. The study has been approved by the Medical Ethics Committee of the Erasmus University Medical Center, Rotterdam

Funding/support The Generation R Study receives financial support from the Erasmus Medical Center, Rotterdam and The Netherlands Organization for Health Research and Development (ZonMw). The general design of Generation R Study is made possible by financial support from the Erasmus MC, University Medical Center, Rotterdam, the Netherlands Organization for Health Research and Development (ZonMw) and the Ministry of Health, Welfare and Sport. Vincent Jaddoe received additional grants from the Netherlands Organization for Health Research and Development (VIDI 016. 136. 361) and European Research Council (ERC Consolidator Grant, ERC-2014CoG-648916).

\section{Disclosure None}

Open Access This article is distributed under the terms of the Creative Commons Attribution 4.0 International License (http:// creativecommons.org/licenses/by/4.0/), which permits unrestricted use, distribution, and reproduction in any medium, provided you give appropriate credit to the original author(s) and the source, provide a link to the Creative Commons license, and indicate if changes were made.

\section{References}

1. Brenner BM, Chertow GM (1993) Congenital oligonephropathy: an inborn cause of adult hypertension and progressive renal injury? Curr Opin Nephrol Hypertens 2:691-695

2. Huxley R, Neil A, Collins R (2002) Unravelling the fetal origins hypothesis: is there really an inverse association between birthweight and subsequent blood pressure? Lancet 360:659-665

3. Lackland DT, Bendall HE, Osmond C, Egan BM, Barker DJ (2000) Low birth weights contribute to high rates of early-onset chronic renal failure in the Southeastern United States. Arch Intern Med 160:1472-1476

4. Brenner BM, Lawler EV, Mackenzie HS (1996) The hyperfiltration theory: a paradigm shift in nephrology. Kidney Int 49:1774-1777

5. Barker DJ, Osmond C, Golding J, Kuh D, Wadsworth ME (1989) Growth in utero, blood pressure in childhood and adult life, and mortality from cardiovascular disease. BMJ 298:564-567

6. Gluckman PD, Hanson MA, Cooper C, Thornburg KL (2008) Effect of in utero and early-life conditions on adult health and disease. N Engl J Med 359:61-73

7. Lim YJ, Kim WS, Kim HS, Choi YH, Cheon JE, Shin SM, Kim IO, Choi JH (2014) Ultrasonographic study of initial size and postnatal growth of kidneys in preterm infants. Neonatology 106:107-113

8. Bakker H, Gaillard R, Franco OH, Hofman A, van der Heijden AJ, Steegers EA, Taal HR, Jaddoe VW (2014) Fetal and infant growth patterns and kidney function at school age. J Am Soc Nephrol 25: 2607-2615

9. White SL, Perkovic V, Cass A, Chang CL, Poulter NR, Spector T, Haysom L, Craig JC, Salmi IA, Chadban SJ, Huxley RR (2009) Is low birth weight an antecedent of CKD in later life? A systematic review of observational studies. Am J Kidney Dis 54:248-261

10. Hinchliffe SA, Sargent PH, Howard CV, Chan YF, van Velzen D (1991) Human intrauterine renal growth expressed in absolute number of glomeruli assessed by the disector method and Cavalieri principle. Lab Investig 64:777-784

11. Butt K, Lim K, Society of O, Gynaecologists of C (2014) Determination of gestational age by ultrasound. J Obstet Gynaecol Can 36:171-183

12. Mook-Kanamori DO, Steegers EA, Eilers PH, Raat H, Hofman A, Jaddoe VW (2010) Risk factors and outcomes associated with firsttrimester fetal growth restriction. JAMA 303:527-534

13. Jaddoe VW, van Duijn CM, Franco OH, van der Heijden AJ, van Iizendoorn MH, de Jongste JC, van der Lugt A, Mackenbach JP, Moll HA, Raat H, Rivadeneira F, Steegers EA, Tiemeier H, Uitterlinden AG, Verhulst FC, Hofman A (2012) The Generation R Study: design and cohort update 2012. Eur J Epidemiol 27:739-756

14. Jaddoe VW, de Jonge LL, Hofman A, Franco OH, Steegers EA, Gaillard R (2014) First trimester fetal growth restriction and cardiovascular risk factors in school age children: population based cohort study. BMJ 348:g14

15. Verburg BO, Mulder PG, Hofman A, Jaddoe VW, Witteman JC, Steegers EA (2008) Intra- and interobserver reproducibility study of early fetal growth parameters. Prenat Diagn 28:323-331

16. Miliku K, Voortman T, Bakker H, Hofman A, Franco OH, Jaddoe VW (2015) Infant breastfeeding and kidney function in school-aged children. Am J Kidney Dis 66:421-428

17. Geelhoed JJ, Taal HR, Steegers EA, Arends LR, Lequin M, Moll HA, Hofman A, van der Heijden AJ, Jaddoe VW (2010) Kidney growth curves in healthy children from the third trimester of pregnancy until the age of two years. The Generation R Study. Pediatr Nephrol 25:289-298

18. Geelhoed JJ, Kleyburg-Linkers VE, Snijders SP, Lequin M, Nauta J, Steegers EA, van der Heijden AJ, Jaddoe VW (2009) Reliability of renal ultrasound measurements in children. Pediatr Nephrol 24: $1345-1353$

19. Bakker H, Kooijman MN, van der Heijden AJ, Hofman A, Franco OH, Taal HR, Jaddoe VW (2014) Kidney size and function in a multi-ethnic population-based cohort of school-age children. Pediatr Nephrol 29:1589-1598

20. Schwartz GJ, Munoz A, Schneider MF, Mak RH, Kaskel F, Warady BA, Furth SL (2009) New equations to estimate GFR in children with CKD. J Am Soc Nephrol 20:629-637

21. Zappitelli M, Parvex P, Joseph L, Paradis G, Grey V, Lau S, Bell L (2006) Derivation and validation of cystatin C-based prediction equations for GFR in children. Am J Kidney Dis 48:221-230

22. Donaghue KC, Chiarelli F, Trotta D, Allgrove J, Dahl-Jorgensen K, International Society for Pediatric and Adolescent Diabetes (2007) ISPAD Clinical Practice Consensus Guidelines 2006-2007. Microvascular and macrovascular complications. Pediatr Diabetes 8:163-170

23. Du Bois D, Du Bois EF (1989) A formula to estimate the approximate surface area if height and weight be known. 1916. Nutrition 5: 303-311, discussion 312-303

24. Sterne JA, White IR, Carlin JB, Spratt M, Royston P, Kenward MG, Wood AM, Carpenter JR (2009) Multiple imputation for missing data in epidemiological and clinical research: potential and pitfalls. BMJ 338:b2393

25. Hoffman CS, Messer LC, Mendola P, Savitz DA, Herring AH, Hartmann KE (2008) Comparison of gestational age at birth based on last menstrual period and ultrasound during the first trimester. Paediatr Perinat Epidemiol 22:587-596

26. Nyengaard JR, Bendtsen TF (1992) Glomerular number and size in relation to age, kidney weight, and body surface in normal man. Anat Rec 232:194-201 
27. Kett MM, Bertram JF (2004) Nephron endowment and blood pressure: what do we really know? Curr Hypertens Rep 6:133-139

28. Luyckx VA, Brenner BM (2010) The clinical importance of nephron mass. J Am Soc Nephrol 21:898-910

29. Bacchetta J, Cochat P, Rognant N, Ranchin B, Hadj-Aissa A, Dubourg L (2011) Which creatinine and cystatin $C$ equations can be reliably used in children? Clin J Am Soc Nephrol 6:552-560

30. Andersen TB, Eskild-Jensen A, Frokiaer J, Brochner-Mortensen J (2009) Measuring glomerular filtration rate in children; can cystatin C replace established methods? A review. Pediatr Nephrol 24:929-941

31. Miller WG, Bruns DE, Hortin GL, Sandberg S, Aakre KM, McQueen MJ, Itoh Y, Lieske JC, Seccombe DW, Jones G, Bunk DM, Curhan GC, Narva AS, National Kidney Disease Education Program IWGoSoAiU (2009) Current issues in measurement and reporting of urinary albumin excretion. Clin Chem 55:24-38

32. Smith GC, Smith MF, McNay MB, Fleming JE (1998) Firsttrimester growth and the risk of low birth weight. N Engl J Med 339:1817-1822

33. Bukowski R, Smith GC, Malone FD, Ball RH, Nyberg DA, Comstock CH, Hankins GD, Berkowitz RL, Gross SJ, Dugoff L, Craigo SD, Timor-Tritsch IE, Carr SR, Wolfe HM, D'Alton ME, Consortium FR (2007) Fetal growth in early pregnancy and risk of delivering low birth weight infant: prospective cohort study. BMJ 334:836

34. Blackburn SB (2003) Renal system and fluid and electrolyte homeostasis. Maternal, fetal and neonatal physiology: a clinical perspective, 4th edn. Saunders, Maryland Heights
35. Schmidt IM, Chellakooty M, Boisen KA, Damgaard IN, Mau Kai C, Olgaard K, Main KM (2005) Impaired kidney growth in lowbirth-weight children: distinct effects of maturity and weight for gestational age. Kidney Int 68:731-740

36. Spencer J, Wang Z, Hoy W (2001) Low birth weight and reduced renal volume in Aboriginal children. Am J Kidney Dis 37:915-920

37. Drougia A, Giapros V, Hotoura E, Papadopoulou F, Argyropoulou M, Andronikou S (2009) The effects of gestational age and growth restriction on compensatory kidney growth. Nephrol Dial Transplant 24:142-148

38. Hoy WE, Bertram JF, Denton RD, Zimanyi M, Samuel T, Hughson MD (2008) Nephron number, glomerular volume, renal disease and hypertension. Curr Opin Nephrol Hypertens 17:258-265

39. Sutherland MR, Gubhaju L, Moore L, Kent AL, Dahlstrom JE, Horne RS, Hoy WE, Bertram JF, Black MJ (2011) Accelerated maturation and abnormal morphology in the preterm neonatal kidney. J Am Soc Nephrol 22:1365-1374

40. Verburg BO, Geelhoed JJ, Steegers EA, Hofman A, Moll HA, Witteman JC, Jaddoe VW (2007) Fetal kidney volume and its association with growth and blood flow in fetal life: the Generation $\mathrm{R}$ Study. Kidney Int 72:754-761

41. Luyckx VA, Bertram JF, Brenner BM, Fall C, Hoy WE, Ozanne SE, Vikse BE (2013) Effect of fetal and child health on kidney development and long-term risk of hypertension and kidney disease. Lancet 382:273-283

42. Hilliard SA, El-Dahr SS (2016) Epigenetics mechanisms in renal development. Pediatr Nephrol 31:1055-1060 